\title{
The Assessment Methods and Learning Approaches in Nursing Students of Kerman University of Medical Sciences in Iran
}

\author{
Sakine Sabzevari, Abbas Abbaszade ${ }^{*}$, Fariba Borhani \\ Department of Nursing, Kerman University of Medical Sciences, Kerman, Iran \\ Email: *A_Abbaszade@kmu.ac.ir \\ Received November $27^{\text {th }}$, 2012; revised December $30^{\text {th }}$, 2012; accepted January $15^{\text {th }}, 2013$
}

\begin{abstract}
The purpose of this paper is to gain insight into the relationship between the conventional methods of assessment in medical surgical courses and students' approaches to learning. In this descriptive correlational study; the sample consisted of 198 undergraduate and postgraduate students studying nursing. Data were obtained using the revised two-factor study process questionnaire (R-SPQ-2F) and the Assessment preference inventory including personal characteristics and assessment methods. The results showed that mean grade for deep learning approaches were a bit higher than surface learning approaches. (Mean \pm Standard error [SE] $34.27 \pm 5.006$ versus Mean \pm Standard error [SE] $31.21 \pm 5.52$ ). The deep and surface approaches were proposed each with a motive and strategy subscale. In this regard; grades of $16.51 \pm 2.73$, $17.75 \pm 3.28$ and $14.6 \pm 3.72,16.61 \pm 2.74$ were obtained for deep motive and strategy and surface motive and strategy respectively. Regarding the relationship between learning approaches and clinical assessment methods; the results of ANOVA test showed significant differences only on surface learning strategy ( $p<$ 0.05 ) and between clinical, oral and practical group project assessments. In respect to the relationship between learning approaches and written assessment methods; there were also strong and significant correlations between True-False questions and a combination of tests groups in deep motive subscale and between project assessment and a combination of tests groups in surface strategy subscale $(p<0.05)$. Suggestions are offered for mixed and new assessment methods and techniques in medical education. In case of some new debates on evaluation, workshops and training courses are recommended.
\end{abstract}

Keywords: Assessment Methods; Learning Approaches; Medical Surgical Nursing Courses; Nursing Students; Student Evaluation

\section{Introduction}

During the past decades it has been evidenced that new graduated nurses are not prepared to do their duties properly. Effective assessment of nursing students during university education would ensure their competency, professional satisfaction as well as their patients' safety (Shipman et al., 2012). Learners' performances are different due to differences of several affecting factors including their learning and training styles, how learners encounter with subjects and use their knowledge (Seif, 2008). In recent years various learning approaches are introduced by learning psychologists and educational experts.

According to individuals' differences and their special style of receiving and organizing new information, it can be expected that if teaching methods are consistent with the learner's learning style, learning process is improved and educational failures are prevented (Bourbonnais et al., 2008). Learning approaches are mental activities that learners use in their study and these approaches guide them in understanding subject organizing and reminding (Park, 1995). According to the studies on learning approaches, there are two basic approaches (deep and surface) in higher education (Duff et al., 2004) and (Diseth, 2007). Deep learning approach leads to real understanding of the subject, and deep and stable learning but surface approach focuses on

*Corresponding author. memorizing information and results in incomplete understanding. Each approach has been formed of two elements: motivation and strategy. The motive tells why the individual decides to learn; while the strategy is about how to improve the learning process (Shokri et al., 2006). In deep approach, students like the subjects and try to understand the subjects with high motive. They have deep strategy in doing their assignments, find the assignments interesting, emphasize on the deep meaning of the subject rather than the surface meaning and investigate the relationship between the subjects. For applying deep learning approach, students' teachers should utilize deep approach in teaching and encourage students to have deep approach and strategy in learning (Parsa \& Saketi, 2006).

As one of the main objectives of the education system is to improve the learning process, teachers should recognize and apply the teaching methods which can lead the student to achieve that goal (Houston et al., 2004, Khomeiran et al., 2006).

Assessment methods might have an effect on nursing students' learning approaches. If the assessments are designed based on deep understanding they can lead to deep learning (Morrison, 2003). Assessment is not appended to curriculum but it is one part of it. After determining educational needs, learning outcomes should be defined and assessment objectives must be cleared and linked to the outcomes. Not only assessment is more effective when the learners have comprehensive 
assessment of their learning and understand their own learning style but also having continuous and comprehensive understanding of their performance is a matter of consideration (Watkins et al., 2007).

To educate competent nurses, teachers should pay attention to learning approaches. In this regard, teaching methods, teachers' roles and assessment have considerable effects on the learning process (Akinsanya \& Williams, 2004); therefore some experts recommend that student assessment process should provide adequate information to students and their teachers to be able to improve students' progress especially in aspect of moral and professional responsibility (Bourbonnais et al., 2008). Although clinical assessment is of great importance but it is often subjective and confusing. (Scouller, 1998) and some teachers and students aren't satisfied with clinical evaluation.

Teachers can improve students' critical thinking through assessment methods (Narenji et al., 2010). Assessment methods can influence the learning approaches of nursing students. Assessments are designed to assess student's understanding rather than their rote learning. Assessments should target students' understanding of knowledge, their use of critical thinking, and their application of knowledge (Leung et al., 2008). Hessler and Humpherys (2008) suggested that student assessment is a valuable method for changing educational methods and curriculum planning in nursing; and also an important source of information to determine the quality of education. Universities and schools have too much responsibility in students' educational progress and student assessments.

\section{Literature Review}

In a study conducted by Harlen (2007) about student assessment criteria, three main paradigms were mentioned: behavior change, merit and making data summary. The assessment of students is used for various different purposes which will have an impact on education process and the curriculum thus it is necessary to emphasize on criteria of validity, reliability and good use of resources and apply them to assessment for formative and summative purposes. According to Leung (2008) based on her study on the impact of assessment methods on learning approaches of nursing students, it was noted that excessive workload of nursing students would decrease their deep learning scores and increase their surface learning scores. There is a negative relationship between students' academic achievements and their surface learning approach. On the other hand, students believed that assessments which were designed based on scenario-based questions, simulated role-play situations and case studies could lead to better critical thinking and knowledge application. Some studies showed that students' assessment results and their educational performance are inversely correlated with surface approach and directly correlated with deep learning approach and indeed assessment methods might have an effect on learning approaches (Parsa \& Saketi, 2006). Some assessment methods that emphasize on data recalling and do not pay enough attention on knowledge application would encourage students to have surface learning approach (Magnussen, 2001).

\section{Nursing Education Issues in Iran}

In Iran, nursing students are selected by National University Entrance Examination after they finish high school. In nursing school, students can study their Bs degree and if they pass further entrance examinations, they can tailor a master or a Ph.D. degree. All these programs are currently taught in Razi School of Nursing in Kerman, Iran. Due to the importance and intrinsic nature of clinical assessments which enable students to obtain a qualification to continue their career in a number of health professions, these tests should be designed and implemented accurately. The most commonly used assessment methods to evaluate medical and surgical nursing courses are listed as multiple choice questions (MCQs), true-false questions, Extended matching Questions (EMQs) for pen and paper testing, work samples, question answering, Objective Structured Clinical examination (OSCE), portfolio, log book, written practical tests and simulation based situations for clinical evaluation. Based on our experiences, students aren't highly qualified and competent in their courses and some of them ask their teachers about the assessment methods of the final examinations and choose their studying style according to the assessment methods only to pass the exams and based on their little knowledge, poor attitude and weak performance would face some problems in clinical situations. Currently, traditional clinical assessments are frequently used for assessments. It is important to determine whether assessment methods lead to deep learning approach or not.

\section{Study Aims}

Due to the importance of medical surgical courses in nursing education, we aimed to investigate the assessment methods of medical surgical courses and their relationship with learning approaches in nursing students of Kerman University of Medical Sciences.

\section{Methods}

It was a descriptive correlational study that evaluated the conventional assessment methods of medical surgical nursing courses and students' learning approaches.

\section{Data Collection}

We used a questionnaire for assessment of students' learning approaches which included the followings: personal characteristics, assessment methods and the revised two-factor study process questionnaire (R-SPQ-2F) that consists of twenty items scored on a five-point Likert scale (from "completely agree" to "completely disagree”) (Leung, 2008). It is suitable for teachers to assess the learning approaches of their students. The revised questionnaire which uses fewer items categorizes students into two different approaches to learning. These are "surface learning approaches" (referring to student intentions in learning by memorizing and reproducing the factual contents of the study materials) and "deep learning approaches" (associated with student intentions in understanding and constructing the meaning of the content to be learned). Both deep and surface approach scales have motive and strategy subscales (Biggs et al., 2001).

Because our students study in Persian language, we translated the questionnaire to Persian and then to English (backward and forward). For content validity, we emailed the translated questionnaire to some experts and requested them to evaluate it. After they approved the questionnaire, we asked 30 
students to complete the questionnaire. Then we evaluated its reliability which was confirmed by alpha $=0.7$. Moreover, the questionnaire's validity and reliability have been also confirmed by Shokri et al. (2006) with alpha $=0.85$ for the deep approach and 0.73 for the surface approach (Shokri et al., 2006).

\section{Sample}

The sample consisted of 240 undergraduate and postgraduate nursing students. A total of 198 students completed the questionnaire, among them, 144 and 54 were undergraduate and postgraduate students respectively. All participants were informed about the purpose of the study and agreed with its protocol.

\section{Data Analysis}

All tests were conducted using SPSS version 18 Software. Variables' normality was tested with Kolmogrov-smirnov test; then we used descriptive statistics (frequency distribution, mean, and standard deviation) as well as analytical tests ( $\mathrm{T}$ test, ANOVA) and Pearson correlation test for data analysis.

This study was approved by the University of Kerman Medical Sciences Committee for Ethics. All students were informed of the purposes of the study and agreed on sharing of their views.

\section{Results}

Most students were female (52.5\%), undergraduate (72.7\%) and single (64.1\%). The average age was $23.42 \pm 5.38$. Most written tests were MCQs (32.3\%), projects (13.1\%) and a combination of methods (42.9\%). For clinical assessment, the most commonly used test formats were bed-side examination (30.3\%), practical projects (31.3\%), oral tests (15.7\%) and a combination of these methods (21.7\%).

Analysis of students' responses showed that item 8 (I sometimes learn topics by rote learning and going over and over until I learn them by heart even if I do not understand them)(x = 3.96), item 2 (I think that I have to work on a topic adequately so that I can make my own conclusions before I am satisfied) $(\bar{X}=3.92)$ and item 10 (I test myself on important topics until I understand them completely) $(\bar{X}=3.82)$ had the highest average scores. On the other hand, item 7 (I do not find my courses very interesting so I don't work on them adequately) $(\bar{X}=2.59$ ), item 17 (I attend most of my classes with questions in mind that I want answers to them) $(\bar{x}=2.69)$ and item 3 (My aim is to pass the courses by doing as little work as possible) $(\bar{X}=2.71)$ had the lowest average scores.

Regarding learning approaches, deep approach score was $34.27 \pm 5.006$ and surface approach score was $31.21 \pm 5.52$. The deep and surface approaches were proposed each with a motive and strategy subscale. In this regard; grades of $16.51 \pm$ 2.73, $17.75 \pm 3.28$ and $14.6 \pm 3.72,16.61 \pm 2.74$ were obtained for deep motive and strategy and surface motive and strategy respectively (Table $\mathbf{1}$ ).

With regard to the learning approaches and personal characteristics, there was an inverse relationship between students' age and surface learning approach $(p<0.05)$ and also between motivation and strategy subscales. Conversely, there were significant differences between mean grades of surface learning approach, motivation and strategy. Post-graduate students' scores in deep approach was more than those of undergraduate students $(p<0.05)$.

Besides, there was no significant difference in learning approaches scores of two genders, but we found significant differences in surface learning approach and motivation scores of student with different marital status as the married students had higher average scores in surface learning approach $(p<0.05)$. In application of clinical assessments and based on ANOVA and post hoc tukey results, we found significant differences only between surface strategy scores of bed-side exams, oral and practical projects $(p<0.05)$ (Table 2). Moreover, in application of written tests and based on ANOVA and post hoc tukey results, we found significant differences between deep motive scores of true-false tests and combined tests and also between surface strategy scores of projects and combined tests $(p<0.05)$ (Table 3).

\section{Discussion}

In this contribution, the multiple-choice questions (MCQs) and project presentations were the most common type of written test items used in postgraduate nursing examinations. Teachers used various types of tests including MCQs, Extended matching questions (EMQs) and essays for students' evaluation.

In addition to written tests, the most commonly used test formats regarding practical tests were bed-side exams and practical projects. $21.7 \%$ of respondents stated that their teachers used a combination of methods (bed-side exams, oral tests and practical projects) for their evaluation. On the contrary, none of the respondents reported using OSCE and logbooks despite their pivotal role in assessment of nursing students and teachers' awareness of their importance. Magnussen (2001) posed that the traditional clinical assessment methods cannot lead to meaningful and deep learning (Magnussen, 2001).

Because assessment methods are based on teaching methods, so it is expected that teachers change their curriculum planning to conduct more effective clinical assessments and shift from subjective conditions to more serious ones. No study has been conducted about common assessment methods in Iran. Regarding students' learning approaches, the deep approach has been used more than the surface approach. Haggis (2003) reported that administration of surface approaches for gaining achievement and success at the end of the semester, predicts poor achievement.

In this study, the scores of deep approach $(34.27 \pm 5.006)$ and surface approach $(31.21 \pm 5.52)$ were more than the study

Table 1.

Mean and standard deviation of learning approaches and strategies scores.

\begin{tabular}{lcccc}
\hline Learning approaches and subscales & $\bar{x}$ & SD & Min & Max \\
\hline Deep motive & 16.51 & 2.73 & 10 & 24 \\
Deep strategy & 17.75 & 3.28 & 6 & 24 \\
Surface motive & 14.60 & 3.72 & 5 & 23 \\
Surface strategy & 16.61 & 2.74 & 9 & 24 \\
Deep approach score & 34.27 & 5.006 & 20 & 48 \\
Surface approach score & 31.21 & 5.52 & 16 & 45 \\
\hline
\end{tabular}


Table 2.

Mean and standard deviation of learning approaches scores according to practical tests.

\begin{tabular}{|c|c|c|c|c|c|c|c|c|c|c|c|c|}
\hline \multirow{2}{*}{ Test types } & \multicolumn{2}{|c|}{ Sur AS } & \multicolumn{2}{|c|}{ Deep AS } & \multicolumn{2}{|c|}{ Sur str } & \multicolumn{2}{|c|}{ Sur mot } & \multicolumn{2}{|c|}{ Deep str } & \multicolumn{2}{|c|}{ Deep mot } \\
\hline & $\bar{x}$ & SD & $\bar{x}$ & $\mathrm{SD}$ & $\bar{x}$ & SD & $\bar{x}$ & SD & $\bar{x}$ & SD & $\bar{x}$ & SD \\
\hline Oral test & 30.12 & 4.80 & 33.12 & 5.86 & 15.38 & 2.75 & 14.74 & 3.56 & 17.19 & 3.66 & 15.93 & 3.06 \\
\hline Bed side procedure & 32.75 & 5.82 & 34.90 & 5.35 & 17.45 & 2.57 & 15.30 & 3.95 & 17.65 & 3.08 & 16.66 & 3.12 \\
\hline OSCE & 27 & 4.24 & 36.50 & 6.36 & 16.50 & 0.70 & 10.50 & 3.53 & 19 & 2.82 & 17.50 & 3.53 \\
\hline Practical project & 30.33 & 5.23 & 33.75 & 4.28 & 16.08 & 2.69 & 14.25 & 3.35 & 18.72 & 2.45 & 16.09 & 2.27 \\
\hline Mixed of oral, procedure and project & 31.30 & 5.71 & 35.25 & 4.72 & 17.09 & 2.71 & 14.20 & 3.96 & 17.66 & 3.22 & 17.27 & 2.37 \\
\hline ANOVA & \multicolumn{2}{|c|}{$\begin{array}{l}\mathrm{F}=2.19 \\
p=0.07\end{array}$} & \multicolumn{2}{|c|}{$\begin{array}{l}\mathrm{F}=1.15 \\
p=0.33\end{array}$} & \multicolumn{2}{|c|}{$\begin{array}{c}\mathrm{F}=4.08 \\
p=0.003\end{array}$} & \multicolumn{2}{|c|}{$\begin{array}{l}\mathrm{F}=1.40 \\
p=0.23\end{array}$} & \multicolumn{2}{|c|}{$\begin{array}{l}\mathrm{F}=0.40 \\
p=0.80\end{array}$} & \multicolumn{2}{|c|}{$\begin{array}{l}\mathrm{F}=1.68 \\
p=0.15\end{array}$} \\
\hline
\end{tabular}

Table 3.

Mean and standard deviation of learning approaches scores according to Written tests.

\begin{tabular}{|c|c|c|c|c|c|c|c|c|c|c|c|c|c|}
\hline \multirow{2}{*}{ Test types } & \multirow{2}{*}{$\mathrm{N}$} & \multicolumn{2}{|c|}{ Deep Mo } & \multicolumn{2}{|c|}{ Deep Str } & \multicolumn{2}{|c|}{ Sur mot } & \multicolumn{2}{|c|}{ Surstr } & \multicolumn{2}{|c|}{ Deep AS } & \multicolumn{2}{|c|}{ surAs } \\
\hline & & $\bar{x}$ & SD & $\bar{x}$ & SD & $\bar{x}$ & SD & $\bar{x}$ & SD & $\bar{x}$ & SD & $\bar{x}$ & SD \\
\hline MCQ & 64 & 16.42 & 3.02 & 16.92 & 3.47 & 14.95 & 3.84 & 16.23 & 2.97 & 33.34 & 5.61 & 31.18 & 5.82 \\
\hline True false & 10 & 14 & 2.49 & 19.1 & 3.10 & 12.40 & 2.59 & 15.80 & 1.331 & 33.10 & 4.70 & 28.20 & 2.85 \\
\hline Essay & 13 & 16.30 & 2.28 & 17.15 & 4.23 & 15.76 & 4.22 & 16.38 & 3.53 & 33.46 & 6.26 & 32.15 & 5.98 \\
\hline Project & 26 & 16.38 & 2.53 & 18.07 & 3.29 & 14 & 3.07 & 15.65 & 1.93 & 33.46 & 3.12 & 29.65 & 4.19 \\
\hline Mixed of above & 85 & 16.95 & 2.53 & 18.22 & 2.89 & 14.60 & 3.79 & 17.31 & 2.80 & 35.17 & 4.00 & 37.91 & 5.69 \\
\hline ANOVA & & \multicolumn{2}{|c|}{$\begin{array}{l}2.811=\mathrm{f} \\
0.027=p\end{array}$} & \multicolumn{2}{|c|}{$\begin{array}{l}2.93=\mathrm{f} \\
0.08=p\end{array}$} & \multicolumn{2}{|c|}{$\begin{array}{l}1.51=\mathrm{f} \\
0.19=p\end{array}$} & \multicolumn{2}{|c|}{$\begin{array}{l}2.83=\mathrm{f} \\
0.02=p\end{array}$} & \multicolumn{2}{|c|}{$\begin{array}{l}1.49=\mathrm{f} \\
0.20=p\end{array}$} & \multicolumn{2}{|c|}{$\begin{array}{l}1.72=\mathrm{f} \\
0.14=p\end{array}$} \\
\hline
\end{tabular}

performed by Nejat (2011) in which she used the same R-SPQ-2F for evaluating nursing students. In a similar study conducted by Shokri (2006), the scores of deep learning approach and surface learning approach were $35 \pm 7.68$ and 26.90 \pm 8.78 respectively. So there was a similarity between his results and that of ours on deep approach. However, this impact was not significant on surface approach (31.21 versus 26.90). Students with higher scores in deep learning are motivated by an interest to have higher internal motive and an intention to use an appropriate approach for learning. Oppositely, students with higher scores in surface learning show an extrinsic motivation, which is accompanied with rote memorization in their learning process.

The quality of learning is related to the students' learning approach and if teachers identify students' characteristics and their learning approach, they can improve the quality of learning. Those students, who only use memorization, do not have deep learning approach and cannot increase their knowledge. A notable proportion of students adopt learning approaches according to assessment methods and the subjects which they think they would be tested in the final examination. If assessment methods emphasize only on recalling facts and data and not on knowledge application and higher order thinking, they can lead to surface learning approach (Seif \& Khayer, 2007).

Assessment is an important component of the learning process in nursing students. It is also a powerful motivator for learning. Students' experiences of assessments can affect their learning styles (Leung et al., 2008). Seif and Khayer's (2007) study on medical and engineering students in Shiraz, Iran, showed high scores for deep learning approach in both groups. High expectation of success leads to deep learning approach. Students, who believe that they would be successful, pay more attention to their lessons and are eager to learn new topics even they take much time to learn. In the light of conclusions, surface learning strategy score in bed-side exams was higher in comparison to other assessment methods. On the other hand, deep motive score in mixed assessment methods was higher in contrast to written tests; which demonstrates higher students' deep motive in these conditions. There weren't any significant differences between deep and surface learning approach scores except between the subscales. The results support the suggestion, by Seif and Khaier (2007) that students with deep learning approach, try to investigate the relationship and integration of different parts of the lessons and assignments. Teachers are expected to encourage students to have deep learning approach. Students can adopt different approaches in different situations. Students, who have surface approach, have surface motive and think of higher education as only a means of finding a good job. It seems that students are not being encouraged to have a desired learning approach at universities.

Analysis of students' characteristics offered that students' age is inversely correlated with surface learning and its motive and strategy subscales. Undergraduate and married students adopt surface approach more often than post-graduate and single students but there weren't any significant correlations between their scores. In addition we couldn't find any significant differences between the results of male and female students in our study. Nonetheless from the research of Shokri et al. we derived that there was a significant relationship between gender and surface approach score which was higher for male students (2006), whereas the study of Parsa and Saketi (2007) showed that deep approach and deep motive scores were higher in females.

According to the results of our study, because postgraduate 
students are older than other students, they have stronger internal motive and intention for deep approach; while married students have surface learning approach due to their endeavors and lack of free time. Explanations for these interesting results could lie in other contextual elements, alongside the cultural factors and educational disciplines which affect learning approaches and styles. (Seif \& Khaier, 2007)

\section{Limitation of the Study}

This research was conducted only on a small size of population. Therefore, research studies with much larger sample size would be required to ensure appropriate generalization of the findings of the study.

\section{Conclusion}

Assessment is a basic component of curriculum planning but despite its importance, many teachers believe that it is often a time-consuming and confusing process. Learning approaches influence students' academic achievements thus deserve special considerations and more investigations. We recommend teachers to use the assessment methods which can encourage students towards deep understanding and critical thinking.

Applying mixed assessment methods in written tests lead to deep learning approach but taking technical examinations without focusing on reflective thinking, problem solving and critical thinking lead to surface learning approach; therefore the aim of students in those circumstances would be only on passing the exams. We recommend teachers to use mixed assessment methods for clinical assessments. Holding special workshops on new assessment methods would be beneficial for clinical teachers.

\section{Acknowledgements}

The authors acknowledge all the students for collaboration in conducting this research. We also acknowledge the Research Council Center of Kerman Medical University for their Support and dedicated work. This paper is part of a Ph.D. dissertation.

\section{REFERENCES}

Akinsanya, C., \& Williams, M. (2004). Concept mapping for meaningful learning. Nurse Educations Today, 24, 41-46. doi:10.1016/S0260-6917(03)00120-5

Biggs, J., Kember, D., \& Leung, D. (2001). The revised two factor study process questionnaire: R-SPQ-2F. British Journal of Educational Psychology, 71, 133-149. doi:10.1348/000709901158433

Bourbonnais, F. F., Langford, S., \& Giannantonio, L. (2008). Development of a clinical assessment tool for baccalaureate nursing students. Nurse Education in Practice, 8, 68-71. doi:10.1016/j.nepr.2007.06.005

Diseth, A. (2007). Approaches to learning, course experience and examination grade among undergraduate psychology students; tests of mediator effects and construct validity. Studies in Higher Education, 32, 373-388. doi:10.1080/03075070701346949

Duff, A., Boley, E., Dunleavy, K., \& Fergusen, J. (2004). The relation- ship between personality approach to learning and academic performance. Personality and Individual Differences, 36, 1907-1920. doi:10.1016/j.paid.2003.08.020

Haggis, T. (2003). Constructing images of ourselves? A critical investigation into approaches to learning research in higher education. British Educational Research Journal, 29, 89-104. doi:10.1080/0141192032000057401

Harlenw (2007). Criteria for evaluating systems for student assessment. Student in Educational Assessment, 33, 15-28.

Hessler, K., \& Humphreys, J. (2008). Student evaluations: Advice for novice faculty. Faculty Forum, 47, 187-190.

Houston, T. K., Clark, J. M., Levine, R. B., Ferenchick, G. S., Bowen, J. L., Branch, W. T. et al. (2004). Outcomes of a national faculty development program in teaching skills: prospective follow-up of 110 internal medicine faculty development teams. Journal of General Internal Medicine, 19, 1220-1227. doi:10.1111/j.1525-1497.2004.40130.x

Khomeiran, R. T., Yekta, Z. P., Kiger, A. M., \& Ahmadi, F. (2006). Professional competence: Factors described by nurses as influencing their development. International Nursing Review, 53, 66-72. doi:10.1111/j.1466-7657.2006.00432.x

Leung, S. F., Mok, E., \& Wong, D. (2008). The impact of assessment methods on the learning of nursing students. Nurse Education Today, 28, 711-719. doi:10.1016/j.nedt.2007.11.004

Magnussen, L. (2001). The use of the cognitive behavior survey to assess nursing student learning. Journal of Nursing Education, 40, 43-46.

Morrison, J. (2003). ABC of learning and teaching in medicine: Assessment. British Medical Journal, 15, 385-387. doi:10.1136/bmj.326.7385.385

Narenji, F., Roozbahani, N., \& Amiri Farahani, L. (2010). The effective education and assessment program on clinical learning of nursing and midwifery instructors and students opinion in Arak University. Arak Medical University Journal, 12, 103-110.

Nejat, N., Koohestani, H., \& Rezaie, K. (2011). The effect of concept mapping on learning approaches in nursing students. Teharn Medical University Journal of Nursing and Midwifery, 17, 22-31.

Park, S. (1995). Implications of learning strategy research for designing computer assisted instruction. Journal of Research in Computing in Education, 27, 435-456.

Parsa, A., \& Saketi, P. (2006). Learning approaches, outcomes and students perception of implemented curriculum. Shiraz Humanities and Social Sciences Journal, 26, 1-23.

Scouller, K. (1998). The influence of assessment method on students, learning approaches: Multiple choice question examination versus assignment essay. Higher Education, 35, 435-472. doi:10.1023/A:1003196224280

Seif, A. A. (2008). Psychology of modern farm (6th ed.). Teharan: Doran.

Seif, D., \& Khayer, M. (2007). The relationship between motivation believes and learning approaches in some engineering and medical students in Shiraz Universities. Journal of Educational Sciences and Psychology, 3, 57-82.

Shipman, D., Roa, M., Hooten, J., \& Wang, Z. J. (2012). Using the analytic rubric as an assessment tool in nursing education: The positive and the Negative. Nurse Education Today, 32, 246-249. doi:10.1016/j.nedt.2011.04.007

Shokri, A., Kadivar, P., Farzad, V., \& Daneshvarpoor, Z. (2006). The thinking styles relationship and achievement. New Cognitive Sciences, 8, 44-52.

Watkins, Ch., Carnell, E., \& Lodge, C. (2007). Effective learning in Classrooms. London: SAGE Pub Co. 